\title{
Efficacy and safety of ipilimumab in elderly patients with pretreated advanced melanoma treated at Italian centres through the expanded access programme
}

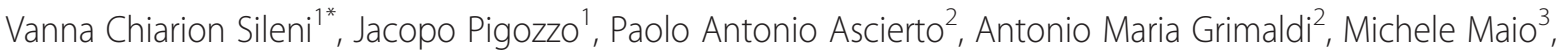 \\ Lorenza Di Guardo ${ }^{4}$, Paolo Marchetti ${ }^{5,6}$, Francesco de Rosa ${ }^{7}$, Carmen Nuzzo ${ }^{8}$, Alessandro Testori ${ }^{9}$, \\ Emilia Cocorocchio ${ }^{10}$, Maria Grazia Bernengo ${ }^{11}$, Michele Guida ${ }^{12}$, Riccardo Marconcini ${ }^{13}$, Barbara Merelli ${ }^{14}$, \\ Giorgio Parmiani ${ }^{15}$, Gaetana Rinaldi ${ }^{16}$, Massimo Aglietta ${ }^{17,18}$, Marco Grosso ${ }^{19}$ and Paola Queirolo ${ }^{19}$
}

\begin{abstract}
Background: Elderly patients with metastatic melanoma have different disease characteristics and a poorer prognosis than younger patients. Data from clinical trials and expanded access programmes (EAPs) suggest ipilimumab confers a consistent survival benefit and has a similar safety profile across different age groups of patients with metastatic melanoma. Here we report the efficacy and safety of ipilimumab $3 \mathrm{mg} / \mathrm{kg}$ in elderly patients enrolled in an EAP in Italy.
\end{abstract}

Methods: Patients aged $>70$ years with pretreated melanoma received ipilimumab $3 \mathrm{mg} / \mathrm{kg}$ every 3 weeks for four doses through an EAP. Tumour response was evaluated at baseline and after completion of induction therapy using immune-related response criteria and patients were monitored throughout the treatment period for adverse events (AEs), including immune-related AEs.

Results: The immune-related disease control rate among 188 evaluable patients was 38\%, including four patients with an immune-related complete response, 24 with an immune-related partial response and 44 with immune-related stable disease. Median progression-free survival (PFS) was 4.0 months and the 1- and 2-year PFS rates were $21 \%$ and 12\%, respectively. Median overall survival (OS) was 8.9 months; 1 - and 2-year OS rates were $38 \%$ and 22\%, respectively. The safety profile of ipilimumab was consistent with that observed in the general population of the Italian EAP and treatment-related AEs generally resolved within a median of 2 weeks with treatment as per protocol-specific guidelines.

Conclusions: These results suggest ipilimumab is a feasible treatment option in elderly patients with metastatic melanoma. Ipilimumab treatment was generally well tolerated and resulted in clinical benefit and extended survival in elderly patients treated at centres in Italy.

Keywords: Melanoma, Ipilimumab, Expanded access, Elderly patients, Treatment outcome, Safety

\section{Background}

Historically, patients with unresectable Stage III or Stage IV (advanced) melanoma had limited treatment options and poor survival outcomes, with older patients having a particularly dismal prognosis $[1,2]$. In 2010, there were an estimated 13.6 melanoma-related deaths per 100000

\footnotetext{
*Correspondence: mgaliz@tiscali.it

1 Melanoma Cancer Unit, Oncology Institute of Veneto IRCCS, Via Gattamelata, 64, 35128 Padua, Italy

Full list of author information is available at the end of the article
}

US inhabitants aged $>65$ years compared with 1.2 per 100000 US inhabitants aged $\leq 65$ years [3]. Current epidemiological data suggest the incidence of melanoma continues to rise in the elderly population despite indications that it has plateaued in younger people $[3,4]$. Combined with a rapid increase in the proportion of elderly people, this has resulted in melanoma becoming an increasingly important health concern in the developed world [5]. 
A number of explanations for the poor prognosis of elderly patients with melanoma have been proposed. Older melanoma patients may be more predisposed to distant metastasis arising from the haematological distribution of tumour cells than younger patients due to changes in lymphatic drainage with ageing [6]. In addition, elderly patients present with thicker melanomas, a higher mitotic rate and increased incidence of ulceration [7], all of which are associated with a worse prognosis [1]. It is likely, however, that the high mortality rates among elderly patients result from a number of age-related variables preventing optimal management of this disease [8].

One confounding factor that may contribute to the poor prognosis of elderly patients with metastatic melanoma is a weakening of the immune system with age, a process referred to as immunosenescence. Therefore, the possibility of using immune-based therapies to promote immune function is an attractive therapeutic option [8,9]. In 2011, the novel immunotherapy agent ipilimumab was the first agent approved for the treatment of patients with advanced melanoma in over three decades [10]. Ipilimumab is a fully human monoclonal antibody directed against cytotoxic T-lymphocyteassociated antigen-4 (CTLA-4), a negative regulator of T-cell-mediated immune responses. By blocking CTLA4, ipilimumab enables prolonged T-cell activation, proliferation and tumour infiltration, thereby potentiating endogenous antitumour responses [11].

Ipilimumab $3 \mathrm{mg} / \mathrm{kg}$ is now approved in over 40 countries for the treatment of adult patients with advanced melanoma. In Phase III trials, ipilimumab treatment significantly extended overall survival (OS) compared with control in both pretreated and treatment-naïve patients $[12,13]$, and follow-up data from clinical trials suggest ipilimumab can provide durable clinical benefit and long-term survival [13-15]. Furthermore, retrospective analyses of clinical trial data suggest the survival benefit conferred by ipilimumab is independent of age, performance status and stage of metastasis, despite the identification of these variables as significant prognostic indicators $[1,16,17]$.

Expanded access programmes (EAPs) provide an opportunity to assess the efficacy and safety of ipilimumab at its approved dose of $3 \mathrm{mg} / \mathrm{kg}$ in elderly patients outside of a clinical trial, in a setting more representative of daily practice. Efficacy and safety results from the Spanish and US EAPs suggest ipilimumab $3 \mathrm{mg} / \mathrm{kg}$ is a feasible treatment option in elderly patients with metastatic melanoma [18-20]. Here, we describe the efficacy and safety of ipilimumab $3 \mathrm{mg} / \mathrm{kg}$ in elderly (> 70 years old) patients with metastatic melanoma treated at Italian centres participating in the European EAP. Data from other patient subgroups treated in the Italian EAP have been published previously $[21,22]$.

\section{Methods}

\section{Patients}

Patients were eligible to be included in the EAP if they had life-threatening unresectable Stage III or Stage IV melanoma and had failed to respond or were intolerant to at least one prior systemic treatment. Ipilimumab was available on physicians' request where no alternative treatment option was available. An Eastern Cooperative Oncology Group (ECOG) performance status of 0,1 or 2 was required, and an interval of at least 28 days since completion of treatment with chemotherapy, biochemotherapy, surgery, radiation, or immunotherapy recommended. The protocol for the EAP was approved by a local independent ethics committee and all participating patients provided signed informed consent before enrolment. The study was approved by the ECs of all participating centers.

\section{Treatment and clinical assessment}

Ipilimumab $3 \mathrm{mg} / \mathrm{kg}$ was administered intravenously over 90 minutes, every 3 weeks for four doses. Disease evaluation was performed at baseline and after completion of induction therapy using immune-related response criteria (irRC) [23]. Clinical response was defined as immune-related complete response (irCR), partial response (irPR), stable disease (irSD) or progressive disease. Immune-related disease control (irDC) was defined as an irCR, irPR or irSD lasting $\geq 3$ months. All patients were monitored for safety throughout the EAP, and adverse events (AEs), including immune-related AEs (irAEs), graded according to the Common Terminology Criteria for Adverse Events, version 3.0.

\section{Statistical analysis}

Patient and disease characteristics were analysed using descriptive statistics with data expressed as relative frequencies (percentages) for discrete variables, or median and range for continuous variables. Progression-free survival (PFS) and OS were estimated using Kaplan-Meier analysis and expressed as median values with corresponding two-sided $95 \%$ confidence intervals (CIs).

\section{Results \\ Patients}

A total of 855 patients participated in the EAP from June 2010 to January 2012 across 55 Italian centres, including 193 patients (23\%) aged $>70$ years (median age, 75 ; range $71-88$ years) of which 27 were aged $\geq 80$ years. Baseline patient and disease characteristics are shown in Table 1 . Of the 193 elderly patients, 132 patients (68\%) received all four doses, 24 (12\%) received three doses, 17 (9\%) received two doses and 20 patients $(10 \%)$ received one dose of ipilimumab $3 \mathrm{mg} / \mathrm{kg}$. Reasons for not completing all four doses of ipilimumab therapy comprised 
Table 1 Baseline patient characteristics

\begin{tabular}{|c|c|c|}
\hline Characteristic $(N=855)$ & $\begin{array}{l}\text { Patients aged } \\
>70 \text { years }\end{array}$ & $\begin{array}{l}\text { Patients aged } \\
\leq 70 \text { years }\end{array}$ \\
\hline Total number of patients & 193 & 662 \\
\hline Median age, years (range) & $75(71-88)$ & $55(16-70)$ \\
\hline Male/female, $n$ (\%) & $112(58) / 81(42)$ & $348(53) / 314(47)$ \\
\hline \multicolumn{3}{|l|}{ ECOG performance status, $n$ (\%) } \\
\hline 0 & $105(54)$ & $458(69)$ \\
\hline 1 & $83(43)$ & $184(28)$ \\
\hline 2 & $5(3)$ & $20(3)$ \\
\hline Time from diagnosis, months (range) & $35(3-280)$ & $40(3-280)$ \\
\hline \multicolumn{3}{|l|}{ LDH level, $n / n(\%)^{\mathrm{a}}$} \\
\hline$<1.10$ ULN & 108/175 (62) & $336 / 545(62)$ \\
\hline$\geq 1.10$ ULN & 67/175 (38) & 209/545 (38) \\
\hline \multicolumn{3}{|l|}{ Number of previous therapies, $n(\%)$} \\
\hline 1 & $128(66)$ & $369(56)$ \\
\hline 2 & $41(21)$ & $192(29)$ \\
\hline$\geq 3$ & $24(13)$ & $101(15)$ \\
\hline \multicolumn{3}{|l|}{ Previous therapy, $n$ (\%) } \\
\hline Dacarbazine & $113(59)$ & $377(57)$ \\
\hline Fotemustine & $54(28)$ & $268(41)$ \\
\hline Platinum-based chemotherapy & $42(22)$ & $274(41)$ \\
\hline Temozolomide & $40(21)$ & $149(23)$ \\
\hline Interferon & $22(11)$ & $172(26)$ \\
\hline BRAF inhibitor & $8(4)$ & $51(8)$ \\
\hline Patients with brain metastases, $n(\%)$ & $17(9)$ & $129(20)$ \\
\hline Patients with liver metastases, $n(\%)$ & $75(39)$ & $264(40)$ \\
\hline
\end{tabular}

${ }^{a} \mathrm{LDH}$ data unavailable for 135 patients.

ECOG, Eastern Cooperative Oncology Group; LDH, lactate dehydrogenase; ULN, upper limit of normal.

disease progression $(n=22)$, death $(n=18)$, deterioration without progression $(n=3)$, AEs unrelated to treatment $(n=4)$, dose skipping $(n=2)$, patient refusal $(n=1)$, loss to follow up $(n=1)$, and unknown reasons $(n=3)$. Only 7 patients (4\%) discontinued for reasons of treatmentrelated toxicity.

\section{Efficacy}

\section{Tumour assessment}

With a median follow-up of 7.9 months (mean 9.7 months; range 1-31 months), the irDC rate (irDCR) among 188 evaluable patients aged $>70$ years was $38 \%$ (Table 2). This included four patients (2\%) with an irCR, 24 (13\%) with an irPR and $44(23 \%)$ with irSD at any time according to irRC, for an immune-related best overall response rate (irBORR) of $15 \%$. Five elderly patients were not evaluable for response due to toxicity $(n=1)$, loss to follow up $(n=1)$, only receiving one dose of ipilimumab $(n=1)$ or unknown reasons $(n=2)$. The median duration of irDC in elderly patients was 11.5 months (95\% CI 9.3-13.7). The irDCR
Table 2 Tumour response

\begin{tabular}{lccc}
\hline $\begin{array}{l}\text { Response } \\
\text { according } \\
\text { to irRC }\end{array}$ & $\begin{array}{c}\text { Aged }>\mathbf{7 0} \\
\text { years } \\
(\boldsymbol{n}=\mathbf{1 8 8})\end{array}$ & $\begin{array}{c}\text { Aged } \geq \mathbf{8 0} \\
\text { years } \\
(\boldsymbol{n}=\mathbf{2 6})\end{array}$ & $\begin{array}{c}\text { Aged } \leq \mathbf{7 0} \\
\text { years } \\
(\boldsymbol{n}=\mathbf{6 4 5})\end{array}$ \\
\hline irCR & $4(2)$ & $0(0)$ & $25(4)$ \\
irPR & $24(13)$ & $1(4)$ & $58(9)$ \\
irSD & $44(23)$ & $7(27)$ & $131(20)$ \\
irPD & $116(62)$ & $18(69)$ & $431(67)$ \\
irBORR & $28(15)$ & $1(4)$ & $83(13)$ \\
irDCR & $72(38)$ & $8(31)$ & $214(33)$ \\
\hline
\end{tabular}

[Note to authors: summarised these data as a table and added data for patients $\geq 80$ years].

irBORR, immune-related best overall response rate; irCR, immune-related complete response; irDCR, immune-related disease control rate; irPD, immunerelated progressive disease; irPR, immune-related partial response; irRC, immune-related response criteria; irSD, immune-related stable disease.

among 26 evaluable patients aged $\geq 80$ years was $31 \%$, comprising one patient (4\%) with an irPR and seven patients (27\%) with irSD. With a median follow-up of 6.7 months (range 1-34), the irDCR among 645 evaluable patients aged $\leq 70$ years was $33 \%$. Of these, 25 patients (4\%) had an irCR, 58 (9\%) an irPR and $131(20 \%)$ had irSD at any time according to irRC. The irBORR in patients aged $\leq 70$ years was therefore $13 \%$.

\section{Survival}

As of April 2013, median PFS in patients $>70$ years old was 4.0 months (95\% CI 3.0-5.0; Figure 1A); 1 - and 2year PFS rates were $21 \%$ and $12 \%$, respectively. By comparison, median PFS in younger patients ( $\leq 70$ years) was 3.7 months (95\% CI 3.4-4.0), with 1- and 2-year PFS rates of $20 \%$ and $11 \%$, respectively. In the elderly patient group ( $>70$ years old), median OS was 8.9 months (95\% CI 7.2-10.6; Figure 1B); 1- and 2-year OS rates were $38 \%$ and $22 \%$, respectively. For patients aged $\leq$ 70 years, median OS was 7.0 months (95\% CI 6.1-7.9); 1 - and 2-year OS rates in the younger age group were $35 \%$ and 19\%, respectively. Differences between age groups in median PFS and median OS were not statistically significant $(P=0.33$ and $P=0.17$, respectively).

\section{Safety}

The safety profile of ipilimumab in elderly patients was comparable to that in the wider EAP population [24]. Of the 193 patients aged $>70$ years treated with ipilimumab, 96 (50\%) reported an $\mathrm{AE}$ of any grade and among these 96 patients, 69 (36\%) had AEs that were considered to be treatment-related. Respective numbers for the 662 patients aged $\leq 70$ years were $303(46 \%)$ and 217 (33\%). The most frequently reported treatment-related AEs among patients aged $>70$ years were pruritus, rash, diarrhoea, nausea and liver toxicity (experienced by at least $2 \%$ of patients; Table 3). Median time to onset of 

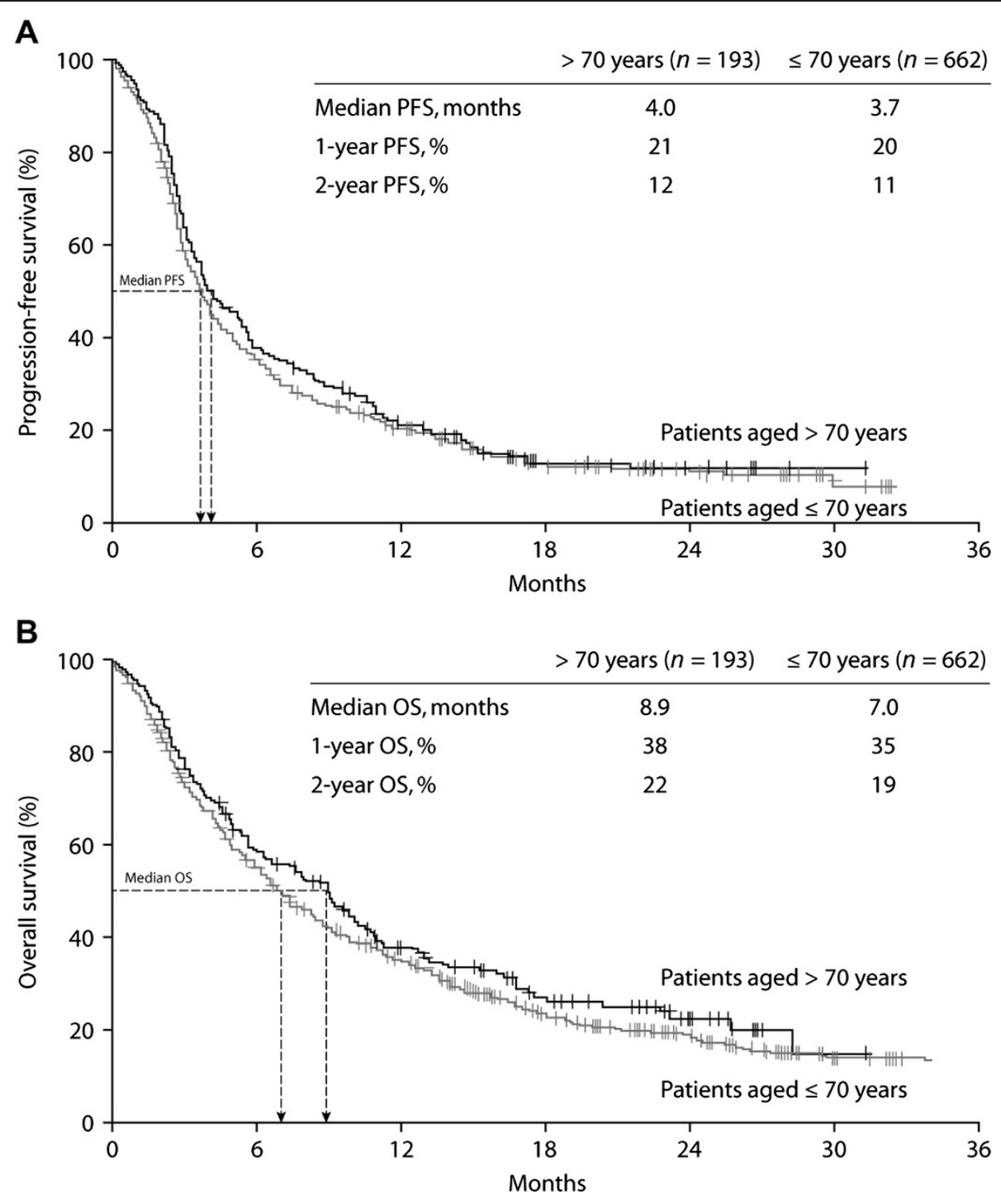

Figure 1 Kaplan-Meier estimates of progression free survival and overall survival by patient ages. A. Progression-free survival. B. OS, overall survival; PFS, progression-free survival.

Table 3 Treatment-related AEs experienced by at least $2 \%$ of patients aged $>70$ or $\leq 70$ years

\begin{tabular}{|c|c|c|c|c|}
\hline \multirow[b]{2}{*}{$\begin{array}{l}\text { Treatment-related AEs experienced } \\
\text { by at least } 2 \% \text { of patients }\end{array}$} & \multicolumn{2}{|c|}{$\begin{array}{l}\text { Patients aged } \\
>70 \text { years } \\
(n=193), n(\%)\end{array}$} & \multicolumn{2}{|c|}{$\begin{array}{c}\text { Patients aged } \\
\leq 70 \text { years } \\
(n=662), n(\%)\end{array}$} \\
\hline & $\begin{array}{l}\text { Any } \\
\text { grade }\end{array}$ & $\begin{array}{l}\text { Grade } \\
\text { III-IV }\end{array}$ & $\begin{array}{l}\text { Any } \\
\text { grade }\end{array}$ & $\begin{array}{l}\text { Grade } \\
\text { III-IV }\end{array}$ \\
\hline Pruritus & $11(6)$ & 0 & $47(7)$ & $1(<1)$ \\
\hline Rash & $19(10)$ & $1(<1)$ & $45(7)$ & $3(<1)$ \\
\hline Diarrhoea & $9(5)$ & $2(1)$ & $51(8)$ & $17(3)$ \\
\hline Nausea & $5(3)$ & 0 & $42(6)$ & $2(<1)$ \\
\hline Liver toxicity & $3(2)$ & $2(1)$ & $16(2)$ & $13(2)$ \\
\hline
\end{tabular}

AEs, adverse events. treatment-related AEs of any grade was 3 weeks (range 0.1-12 weeks). Grade III-IV AEs were reported by 19 patients $(10 \%)$ and considered ipilimumab-related in 11 patients (6\%). Median time to onset of treatment-related Grade III-IV AEs was 6 weeks (range 3-10 weeks). AEs were generally reversible with treatment as per protocolspecific guidelines. Median time to resolution of treatmentrelated AEs of any grade was 2.0 weeks (range 0.1-4), compared with a median of 1.7 weeks (0.1-11.1) among all patients treated in the EAP in Italy [24].

\section{Discussion}

Elderly patients with metastatic melanoma have higher rates of overall and disease-specific mortality than younger patients [7]. Furthermore, older patients are more likely to have existing comorbidities, which often result 
in their exclusion from clinical trials of investigative new therapies [25]. The EAP in Italy provided the opportunity to assess the efficacy and safety of ipilimumab $3 \mathrm{mg} /$ $\mathrm{kg}$ in elderly patients with advanced melanoma outside of a clinical trial setting.

Most other subgroup analyses have used a cut-off age of 65 years when reporting the use of ipilimumab in elderly patients $[12,19,20,26]$. Our results suggest ipilimumab treatment is equally effective and safe in patients with advanced melanoma who are aged over or under 70 years. This higher cut-off age may be more relevant to the challenges associated with cancer treatment in an aging society. Indeed, the cut-off for many clinical cancer studies is now 70 years and this is expected to be revised upwards so that 75 years may soon be the standard upper age limit for inclusion in a clinical trial [27,28]. Among the 855 patients who participated in the EAP in Italy, almost one quarter were aged $>70$ years and were eligible for treatment. This figure is consistent with the proportion of patients $>70$ years diagnosed with melanoma in Italy as recorded in the Italian cancer registry, demonstrating that the elderly patients treated as part of the EAP can be considered as representative of the general population of patients $>70$ years with melanoma.

Elderly patients had long-lasting clinical responses and prolonged survival with ipilimumab $3 \mathrm{mg} / \mathrm{kg}$. The irBORR and irDCR in patients aged $>70$ years were similar to those observed in the wider population of the Italian EAP [24] and in 30 elderly patients ( $\geq 70$ years old) treated at Spanish centres through the EAP [20]. One- and 2-year survival rates of $38 \%$ and $22 \%$ are also comparable with those reported for the total population and consistent with results from the US EAP, in which 1-year survival rates for patients $<65$ years or $\geq 65$ years were $38 \%$ and $37 \%$, respectively [18]. In the Italian EAP, PFS and OS survival curves were comparable between older and younger patients. Although there was a tendency for survival to be better in the elderly patient cohort, the differences in median PFS and median OS between older and younger patients were not statistically significant and were most likely to chance since the inclusion and exclusion criteria were the same for all patients, as was the follow-up duration, This finding is also consistent with prespecified subgroup analyses of data from the Phase III trial of ipilimumab in pretreated patients, in which the survival benefit with ipilimumab monotherapy compared with gp100 monotherapy was slightly but not significantly greater in patients aged $\geq 65$ years than in younger patients $(<65$ years) $[12,16]$. Similarly, in the registrational trial of vemurafenib, an inhibitor of mutated BRAF, no differences in survival or response were reported between older ( $\geq 65$ years) and younger patients ( $<65$ years) with metastatic melanoma [29].

Ipilimumab is associated with irAEs, which may reflect the proposed mechanism of action [11,30]. Most irAEs are mild or moderate and, provided they are recognised early, can be resolved effectively with appropriate management [31]. Among patients $>70$ years treated in the Italian EAP, ipilimumab was generally well tolerated with only $6 \%$ of patients experiencing Grade III-IV treatment-related AEs. In addition, most elderly patients received all four doses or discontinued treatment for reasons other than toxicity. The AE profile of ipilimumab in patients aged > 70 years was again consistent with that observed in the overall EAP population, with a similar incidence of Grade III-IV treatment-related AEs and no unexpected toxicities. The results were also in line with subgroup analyses of safety data from patients treated with ipilimumab in clinical trials, EAPs or as standard of care $[12,19,24]$. In the US EAP, $11 \%$ patients aged $\geq 65$ years had a Grade IIIIV irAE compared with $7 \%$ patients aged $<65$ years [19]. Similarly, only four elderly patients (13\%) treated in the Spanish EAP had a Grade III-V AE and no patients discontinued treatment due to toxicity [20]. Taken together, these results suggest that increased age does not compromise the tolerability of ipilimumab treatment. However, this requires further validation in very elderly patients, as recent data suggest that patients aged $\geq 75$ years treated with vemurafenib are more likely to experience AEs than younger patients, including secondary skin lesions, decreased appetite and cardiac disorders [32].

The results of this EAP are particularly relevant as they show that ipilimumab provides a consistent survival benefit in patients aged over or under 70 years, despite the fact that the immune system often becomes less active in elderly people. Indeed, immunosenescence is an important risk factor for melanoma and is thought to affect all components of the immune system $[8,9]$. With regard to adaptive immunity, an age-related reduction in the proportion of naive $\mathrm{T}$ cells occurs due to impaired T-cell development in the thymus. Functional defects in T-cell activity are also observed, partly due to a loss in costimulatory molecules, including CD28 [33]. However, ipilimumab may be particularly appropriate for the treatment of elderly patients because the expression of coinhibitory receptors such as CTLA-4 increases with age [34]. There is therefore a strong rationale for using antiCTLA-4 therapy to treat elderly patients with metastatic melanoma in order to enhance adaptive immunity against this disease.

Most data regarding the use of ipilimumab in older patients are provided by EAP analyses. The EAPs are a valuable source of information regarding the efficacy and safety of ipilimumab outside of clinical trials, but they are also subject to limitations due to their retrospective, nonrandomised nature and the specific data collected. For example, the effect of patient comorbidities on the efficacy and safety of ipilimumab in elderly patients treated in the Italian EAP could not be assessed, 
as only limited comorbidity data were collected as part of the programme. In addition, it was not possible to stratify patients by activities of daily living (ADL) and instrumental ADL scales, which would have better characterised the patient population. However, these preliminary results suggest that ipilimumab is a safe and effective treatment option for elderly patients with metastatic melanoma. Continued follow-up in this patient population will provide long-term efficacy and safety results.

\section{Conclusions}

Results from this analysis of elderly patients with advanced melanoma treated as part of an EAP in Italy suggest that ipilimumab $3 \mathrm{mg} / \mathrm{kg}$ is a well-tolerated treatment option, providing clinical benefit and extending survival in these patients. In addition, the clinical activity and safety profiles of ipilimumab in patients aged $>70$ years were consistent with those observed in the wider population of the EAP. Although this analysis is subject to limitations, these results suggest that age should not be a deciding factor when considering whether to use ipilimumab to treat patients with advanced melanoma.

\section{Abbreviations}

AE: Adverse event; Cl: Confidence interval; CTLA-4: Cytotoxic T-lymphocyteassociated antigen-4; EAP: Expanded access programme; ECOG: Eastern Cooperative Oncology Group; irAE: Immune-related adverse event; irBORR: Immune-related best overall response rate; irCR: Immune-related complete response; irDC: Immune-related disease control; irDCR: Immunerelated disease control rate; irRC: Immune-related response criteria; PFS: Progression-free survival; OS: Overall survival.

\section{Competing interests}

Vanna Chiarion Sileni has received travel expenses for medical meetings and conferences and honoraria for advisory boards and consultancy from Bristol-Myers Squibb, GlaxoSmithKline, Merck Sharp \& Dohme and Roche-Genentech. Paolo Ascierto has served in a consultancy/advisory role for Bristol-Myers Squibb, Merck Sharp \& Dohme, Roche-Genentech, GlaxoSmithKline, Amgen and Celgene; he has also received research funding from Bristol-Myers Squibb, and honoraria from Bristol-Myers Squibb, Merck Sharp \& Dohme, Roche-Genentech and GlaxoSmithKline. Michele Maio has had an advisory role and received funding for communication programs from Bristol-Myers Squibb, Roche-Genentech and Merck Sharp \& Dohme and has received research funding from Bristol-Myers Squibb. Paolo Marchetti has had advisory roles for Bristol-Myers Squibb, GlaxoSmithKine and Novartis. Alessandro Testori has received honoraria and travel reimbursement for advisory boards from Bristol-Myers Squibb. Paola Queirolo has served in a consultant or advisory role for Bristol-Myers Squibb, GlaxoSmithKline and Roche-Genentech. All remaining authors have declared no conflicts of interest.

\section{Authors' contributions}

All authors made substantial contributions to the acquisition and interpretation of data, were involved in drafting the article or revising it critically for important intellectual content and provided final approval of the version to be published.

\section{Acknowledgements}

The authors would like to thank the patients and investigators who participated in the European EAP.

\section{Funding}

This work was supported in part by the Associazione Italiana per la Ricerca sul Cancro, the Italian Ministry of Health, via the Ricerca Finalizzata 2010. The EAP was sponsored by Bristol-Myers Squibb (BMS). Editorial and writing assistance was provided by StemScientific, funded by BMS. Statistical support was provided by Clinical Research Services, funded by BMS.

\section{Author details}

'Melanoma Cancer Unit, Oncology Institute of Veneto IRCCS, Via Gattamelata, 64, 35128 Padua, Italy. ${ }^{2}$ Unit of Melanoma, Cancer Immunotherapy and Innovative Therapy, Istituto Nazionale Tumori Fondazione "G. Pascale", Naples, Italy. ${ }^{3}$ Medical Oncology and Immunotherapy Division, University Hospital of Siena, Istituto Toscano Tumori, Siena, Italy. ${ }^{4}$ Medical Oncology, National Cancer Institute, Milan, Italy. ${ }^{5}$ Medical Oncology, Dermopathic Institute of the Immaculate IDI-IRCCS, Rome, Italy. ${ }^{6}$ Medical Oncology, Sant'Andrea Hospital, University Sapienza, Rome, Italy. ${ }^{7}$ Immunotherapy Unit, Romagna National Cancer Institute, Meldola, Italy. ${ }^{8}$ Department of Medical Oncology A, Regina Elena National Cancer Institute, Rome, Italy. ${ }^{9}$ Divisione melanoma e sarcomi muscolo-cutanei, Istituto Europeo di Oncologia, Milan, Italy. ${ }^{10}$ Melanoma Medical Oncology Division, Istituto Europeo di Oncologia, Milan, Italy. ${ }^{11}$ University Hospital St John the Baptist, Turin, Italy. ${ }^{12}$ Medical Oncology Department, National Cancer Research Centre, "Giovanni Paolo II", Bari, Italy. ${ }^{13}$ University Hospital Pisa, "Gathered Hospitals of Santa Chiara", Pisa, Italy.

${ }^{14}$ Department of Oncology and Hematology, Unit of Clinical and Translational Research, "Papa Giovanni XXIII" Hospital, Bergamo, Italy. ${ }^{15}$ Unit of Immuno-Biotherapy of Melanoma, San Raffaele Hospital, Milan, Italy. ${ }^{16}$ "Paolo Giaccone" Polyclinic University Hospital, Palermo, Italy. ${ }^{17}$ Institute of Cancer Research and Treatment, Piedmont Oncology Foundation, Candiolo, Italy. ${ }^{18}$ University of Torino, Turin, Italy. ${ }^{19}$ Medical Oncology A, National Institute for Cancer Research, Genoa, Italy.

Received: 11 December 2013 Accepted: 17 March 2014 Published: 4 April 2014

\section{References}

1. Balch CM, Gershenwald JE, Soong SJ, Balch CM, Gershenwald JE, Soong SJ, Thompson JF, Atkins MB, Byrd DR, Buzaid AC, Cochran AJ, Coit DG, Ding S, Eggermont AM, Flaherty KT, Gimotty PA, Kirkwood JM, McMasters KM, Mihm MC Jr, Morton DL, Ross MI, Sober AJ, Sondak VK: Final version of 2009 AJCC melanoma staging and classification. J Clin Oncol 2009, 27:6199-6206.

2. Korn EL, Liu PY, Lee SJ, Chapman JA, Niedzwiecki D, Suman VJ, Moon J, Sondak VK, Atkins MB, Eisenhauer EA, Parulekar W, Markovic SN, Saxman S, Kirkwood JM: Meta-analysis of phase II cooperative group trials in metastatic stage IV melanoma to determine progression-free and overall survival benchmarks for future phase II trials. J Clin Oncol 2008, 26:527-534.

3. Bethesda M: SEER Cancer Statistics Review, 1975-2010. National Cancer Institute; 2012. Available at [http://seer.cancer.gov/statfacts/html/melan.html] (1 July 2013, date last accessed).

4. Jemal A, Siegel R, Xu J, Ward E: Cancer statistics, 2010. CA Cancer J Clin 2010, 60:277-300.

5. Chao C, Martin RC, Ross Ml, Reintgen DS, Edwards MJ, Noyes RD, Hagendoorn $\sqcup$, Stromberg AJ, McMasters KM: Correlation between prognostic factors and increasing age in melanoma. Ann Surg Oncol 2004, 11:259-264.

6. Conway WC, Faries MB, Nicholl MB, Terando AM, Glass EC, Sim M, Morton DL: Age-related lymphatic dysfunction in melanoma patients. Ann Surg Oncol 2009, 16:1548-1552.

7. Macdonald JB, Dueck AC, Gray RJ, Wasif N, Swanson DL, Sekulic A, Pockaj BA: Malignant melanoma in the elderly: different regional disease and poorer prognosis. J Cancer Educ 2011, 2:538-543.

8. Hegde UP, Chakraborty N, Kerr P, Grant-Kels JM: Melanoma in the elderly patient: relevance of the aging immune system. Clin Dermatol 2009, 27:537-544.

9. Hegde UP, Grant-Kels JM: Metastatic melanoma in the older patient: special considerations. Clin Dermatol 2013, 31:311-316.

10. Eggermont $A M M$, Robert $C:$ New drugs in melanoma: It's a whole new world. Eur J Cancer 2011, 47:2150-2157.

11. Wolchok JD, Hodi FS, Weber JS, Allison JP, Urba WJ, Robert C, O'Day SJ, Hoos A, Humphrey R, Berman DM, Lonberg N, Korman AJ: Development of ipilimumab: a novel immunotherapeutic approach for the treatment of advanced melanoma. Ann N Y Acad Sci 2013, 1291:1-13.

12. Hodi FS, O'Day SJ, McDermott DF, Weber RW, Sosman JA, Haanen JB, Gonzalez R, Robert C, Schadendorf D, Hassel JC, Akerley W, van den Eertwegh AJ, Lutzky J, Lorigan P, Vaubel JM, Linette GP, Hogg D, Ottensmeier CH, Lebbé C, Peschel C, Quirt I, Clark JI, Wolchok JD, Weber JS, Tian J, Yellin MJ, Nichol GM, Hoos A, Urba WJ: Improved survival with ipilimumab in patients with metastatic melanoma. N Engl J Med 2010, 363:711-723. 
13. Robert C, Thomas L, Bondarenko I, O'Day S, JW MD, Garbe C, Lebbe C, Baurain JF, Testori A, Grob JJ, Davidson N, Richards J, Maio M, Hauschild A, Miller WH Jr, Gascon P, Lotem M, Harmankaya K, Ibrahim R, Francis S, Chen TT, Humphrey R, Hoos A, Wolchok JD: Ipilimumab plus dacarbazine for previously untreated metastatic melanoma. N Engl J Med 2011, 364:2517-2526.

14. Lebbé C, Weber JS, Maio M, Neyns B, Harmankaya K, Hamid O, O'Day S, Chin KM, Opatt McDowell D, Cykowski L, McHenry B, Wolchok JD: Long-term survival in patients with metastatic melanoma who received ipilimumab in four phase II trials. J Clin Oncol 2013, 31(suppl):abstr 9053.

15. Prieto PA, Yang JC, Sherry RM, Hughes MS, Kammula US, White DE, Levy CL, Rosenberg SA, Phan GQ: CTLA-4 blockade with ipilimumab: long-term follow-up of 177 patients with metastatic melanoma. Clin Cancer Res 2012, 18:2039-2047

16. Lebbé $C$, McDermott DF, Robert $C$, Lorigan P, Ottensmeier $\mathrm{CH}$, Wolchok J, Garbe C, Messina M, Hoos A, Weber JS: Ipilimumab improves survival in previously treated advanced melanoma patients with poor prognostic factors: subgroup analysis from a phase III trial. Ann Oncol 2010, 21(suppl 8):abstr 13240

17. Robert C, Ghiringhelli F: What is the role of cytotoxic T lymphocyteassociated antigen 4 blockade in patients with metastatic melanoma? Oncologist 2009, 14:848-861.

18. Lawrence D, McDermott D, Hamid O, Weber J, Wolchok J, Richards J, Minor D, Pavlick A, Sznol M, Hwu P, Urba W, Amin A, Bennett K, Michener T, Balogh A, Hodi FS: Treatment of Patients (pts) with Stage III or IV Melanoma on an Ipilimumab (Ipi) Expanded Access Program (EAP): Results for $3 \mathrm{mg} / \mathrm{kg}$ Cohort. Hollywood, USA: Society for Melanoma Research (SMR) Congress; 2012.

19. Lawrence D, McDermott D, Hamid O, Weber J, Wolchok J, Richards J, Amin A, Bennett K, Balogh A, Hodi FS: Ipilimumab (IPI) Expanded Access Program (EAP) for patients (pts) with Stage III/IV melanoma: safety data by subgroups. Ann Oncol 2012, 23(suppl 9):abstr 1129P.

20. Lopez Martin JA, Gonzalez Cao M, Sereno M, Mayordomo J, Hidalgo M, Campos B, Cumplido D, Zambrana F, Medina J, Berrocal A: Ipilimumab in older patients: Spanish melanoma multidisciplinary group (GEM) experience in the expanded access programme. Ann Oncol 2012, 23(suppl 9):abstr 3233.

21. Del Vecchio M, Di Guardo L, Ascierto PA, Grimaldi AM, Sileni VC, Pigozzo J, Ferraresi V, Nuzzo C, Rinaldi G, Testori A, Ferrucci PF, Marchetti P, De Galitiis F, Queirolo P, Tornari E, Marconcini R, Calabrò L, Maio M: Efficacy and safety of ipilimumab $3 \mathrm{mg} / \mathrm{kg}$ in patients with pretreated, metastatic, mucosal melanoma. Eur J Cancer 2014, 50:121-127.

22. Maio M, Danielli R, Chiarion-Sileni V, Pigozzo J, Parmiani G, Ridolfi R, De Rosa F, Del Vecchio M, Di Guardo L, Queirolo P, Picasso V, Marchetti P, De Galitiis F, Mandalà M, Guida M, Simeone E, Ascierto PA: Efficacy and safety of ipilimumab in patients with pre-treated, uveal melanoma. Ann Oncol 2013, 24:2911-2915.

23. Wolchok JD, Hoos A, O'Day S, Weber JS, Hamid O, Lebbé C, Maio M, Binder M, Bohnsack O, Nichol G, Humphrey R, Hodi FS: Guidelines for the evaluation of immune therapy activity in solid tumors: immune-related response criteria. Clin Cancer Res 2009, 15:7412-7420.

24. Queirolo P, Spagnolo F, Altomonte M, Chiarion-Sileni V, Pigozzo J, Del Vecchio M, Di Guardo L, Ridolfi R, Scoppola A, Francesco Ferrucci P, Ferraresi V, Grazia Bernengo M, Guida M, Marconcini R, Mandalà M, Parmiani G, Rinaldi G, Aglietta M, Simeone E, Antonio Ascierto P: Italian cohort of the ipilimumab Expanded Access Programme: efficacy, safety and correlation with mutation status in metastatic melanoma patients. J Clin Oncol 2013, 31(suppl):abstr 9070.

25. Aapro MS, Köhne C-H, Cohen HJ, Extermann M: Never too old? Age should not be a barrier to enrollment in cancer clinical trials. Oncologist 2005, 10:198-204.

26. Chandra S, Madden KM, Kannan R, Pavlick AC: Evaluating the safety of anti-CTLA-4 therapy in elderly patients with unresectable melanoma. J Clin Oncol 2013, 31(suppl):abstr 9063.

27. Balducci L: Geriatric oncology: challenges for the new century. Eur J Cancer 2000, 36:1741-1754.

28. Chustecka Z: Older Patients With Cancer Need Geriatric Assessment. In MedScape Multispecialty News. ; 2012. Available at [http://www.medscape. com/viewarticle/773479] (12 February 2014, date last accessed).

29. Chapman PB, Hauschild A, Robert C, Larkin JMG, Haanen JBAG, Ribas A, Hogg D, Hamid O, Ascierto PA, Testori A, Lorigan P, Dummer R, Sosman JA, Garbe C, Maio M, Nolop KB, Nelson BJ, Joe AK, Flaherty KT, MCArthur GA: Updated overall survival (OS) results for BRIM-3, a phase III randomized, open-label, multicenter trial comparing BRAF inhibitor vemurafenib (vem) with dacarbazine (DTIC) in previously untreated patients with BRAF V600E-mutated melanoma. J Clin Oncol 2012, 30(suppl):abstr 8502^

30. Weber JS, Dummer R, de Pril V, Lebbé C, Hodi FS: MDX010-20 Investigators.I. Patterns of onset and resolution of immune-related adverse events of special interest with ipilimumab: detailed safety analysis from a phase 3 trial in patients with advanced melanoma. Cancer 2013, 119:1675-1682.

31. Weber JS, Kahler KC, Hauschild A: Management of immune-related adverse events and kinetics of response with ipilimumab. J Clin Oncol 2012, 30:2691-2697.

32. Larkin JMG, Del Vecchio M, Ascierto PA, Schachter J, Garbe C, Neyns B, Mandala M, Lorigan P, Miller WH, Guminski AD, Berking C, Rutkowski P, Queirolo P, Hauschild A, Arance AM, Brown MP, Mitchell L, Veronese ML, Blank CU: Open-label, multicenter safety study of vemurafenib in patients with BRAFV600 mutation-positive metastatic melanoma. J Clin Oncol 2013, 31(suppl):abstr 9046.

33. Wu D, Meydani SN: Age-associated changes in immune and inflammatory responses: impact of vitamin E intervention. J Leuk Biol 2008, 84:900-914.

34. Yalcin AD, Gorczynski RM, Kahraman MS, Demirel MU, Terzioglu E: CD40, CD45 CTLA-4 levels are elevated in healthy older adults. Clin Lab 2012, 58:449-456.

doi:10.1186/1756-9966-33-30

Cite this article as: Chiarion Sileni et al.: Efficacy and safety of

ipilimumab in elderly patients with pretreated advanced melanoma treated at Italian centres through the expanded access programme. Journal of Experimental \& Clinical Cancer Research 2014 33:30.

\section{Submit your next manuscript to BioMed Central and take full advantage of:}

- Convenient online submission

- Thorough peer review

- No space constraints or color figure charges

- Immediate publication on acceptance

- Inclusion in PubMed, CAS, Scopus and Google Scholar

- Research which is freely available for redistribution

Submit your manuscript at www.biomedcentral.com/submit
C) Biomed Central 